\title{
Andando na contramáo: o destino dos indivíduos com transtorno mental que cometem crimes no Brasil
}

\section{| ${ }^{1}$ Aline Sanches Oliveira, ${ }^{2}$ Fernando Machado Vilhena Dias |}

Resumo: A reforma psiquiátrica no Brasil possibilitou, entre outros benefícios, a substituição do modelo médico psiquiátrico pelo modelo de atenção psicossocial. A internação psiquiátrica passou a ser contraindicada, exceto nos casos em que os recursos extra-hospitalares forem insuficientes ou quando indicada judicialmente. Nesses casos, a assistência aos portadores de sofrimento mental autores de delito é realizada nos Estabelecimentos de Custódia e Tratamento Psiquiátrico (ECTP), onde esses indivíduos são internados para o cumprimento da medida de segurança imposta. Entre os anos de 2015 e 2016, o Mecanismo Nacional de Combate e Prevenção à Tortura (MNCPT) realizou a inspeção de unidades de privação de liberdade, divulgando relatórios através dos quais descreve sua atual realidade. Até o momento, foram visitados cinco estabelecimentos de custódia, nos estados do Pará, Paraíba, Rio Grande do Sul, Rondônia e São Paulo. Este artigo discute o direito à saúde no contexto dos ECTPs. Circulando entre os domínios do direito e da medicina, essa população tem seus direitos humanos violados e, apesar de distantes geograficamente, a opinião é unânime: os avanços na assistência em saúde mental não contemplaram os ECTPs, que ainda preservam características asilares.

\footnotetext{
> Palavras-chave: Hospitais de Custódia e Tratamento Psiquiátrico; crime; doença mental; medida de segurança, Rede de Atenção Psicossocial.
}

\footnotetext{
${ }^{1}$ Escola de Medicina, Universidade Federal de Ouro Preto-MG, Brasil (alinesanc@gmail.com). ORCID: 0000-0003-2606-2245

${ }^{2}$ Escola de Medicina, Universidade Federal de Ouro Preto-MG, Brasil (fernandomvdias@hotmail.com). ORCID: 0000-0002-5538-4852
}

Recebido em: 02/04/2017

Revisado em: 15/10/2017 Aprovado em: 04/06/2018 


\section{Introdução}

As pessoas com transtorno mental sempre existiram na humanidade e, independente da época, a origem dessas doenças constantemente intrigou o ser humano. A doença mental, que na Grécia Antiga representava um privilégio, passou a ser estigmatizada desde a Idade Média, quando esses indivíduos foram considerados uma aberraçáo, possuídos por uma entidade demoníaca e, por isso, merecedores de perseguiçóes e puniçóes severas. Assim, por muito tempo e em diversas partes do mundo, foram isolados da sociedade em instituiçóes chamadas de asilos ou manicômios (FERRAZ, 2016).

A abordagem da saúde mental e a forma de tratar esses pacientes passaram a ser questionadas e, gradativamente, surgiram alguns movimentos em defesa dessa população. Historicamente, dois principais marcos simbolizaram essa evolução: no século XVIII, o médico francês Phillippe Pinel, apesar de ainda conceber o isolamento como necessário, separou os doentes mentais das demais pessoas marginalizadas e libertou-os das correntes, já que eram mantidos acorrentados (ODA; DALGALARRONDO, 2004). Posteriormente, no final da década de 1970, o médico italiano Franco Basaglia liderou o Movimento da Psiquiatria Democrática Italiana, que levou à abolição dos manicômios nesse país (AMARANTE, 2009).

Sua atuação foi de grande influência na reforma vivenciada pelo Brasil, onde, também no final da década de 1970, profissionais da saúde mental denunciaram as condições dos hospitais psiquiátricos, dando início ao movimento pela Reforma Psiquiátrica (FERRAZ, 2016). O movimento seguiu-se com inúmeras reivindicaçóes, culminando, em 2001, com a aprovação da Lei no 10.216, proposta em 1989 pelo deputado Paulo Delgado - PT/MG (BRASIL, 2001).

Concomitantemente à luta antimanicomial, outros eventos importantes aconteciam no país, como a Reforma Sanitária e a promulgação da Constituição Federal, em 1988, que, em seus artigos 196 a 200, estabeleceu os princípios e atribuições do Sistema Único de Saúde, garantindo a saúde como direito de todos e dever do Estado (BRASIL, 1988). Diante dessa realidade, foram criadas alternativas no intuito de substituir a psiquiatria tradicional baseada na abordagem sobretudo medicamentosa por uma psiquiatria sustentada em novos dispositivos e novas tecnologias de assistência (BRASIL, 2013a). 
Desse modo, foi proposta a criação de uma rede substitutiva, composta, dentre outros, pelos Centros de Atenção Psicossocial (CAPS), Núcleo de Atenção Psicossocial, Centro de Atenção Diária, Hospitais Dia, leitos psiquiátricos em hospitais gerais, Serviço Residencial Terapêutico e o Programa "De volta pra casa" (BRASIL, 2003; BRASIL, 2011). Outro modelo instituído foi o matriciamento, através do qual se propóe o atendimento com base na construção compartilhada de propostas de intervenção pedagógico-terapêutica, com a integração da rede de saúde mental e a atenção básica (CHIAVERINI, 2011). Através dessas ações intersetoriais e trabalhos interdisciplinares, busca-se a superação da internação como única abordagem no âmbito da saúde mental.

De acordo com a Lei no 10.216/01, a internação da pessoa com sofrimento mental será indicada somente quando o tratamento fora do hospital se mostrar ineficaz. Para tal, existem três possibilidades: a internação voluntária, com o consentimento do paciente; a involuntária, sem consentimento e a pedido de outra pessoa; e a compulsória, que é determinada pela justiça (BRASIL, 2001).

A internação compulsória destina-se a situações específicas, quando já se esgotaram todos os outros recursos de intervenção e o indivíduo apresenta alto risco para si e para terceiros, podendo ser solicitada mediante laudo médico circunstanciado que caracterize os seus motivos e determinada pelo juiz competente (BRASIL, 2001). Um exemplo dessa modalidade de internação encontra-se na internação de usuários e dependentes químicos em situação de vulnerabilidade social, intervenção amplamente discutida sob à luz da Lei no 10.216/01 devido a um possível uso higienista dessa política (PÊCEGO; GERIAGE NETO, 2013).

As pessoas com sofrimento mental autoras de delitos também se enquadram nesse tipo de internação e, nesses casos, são aplicadas as Medidas de Segurança, estabelecidas pelos artigos 96 a 99 do Código Penal (CP) Brasileiro (BRASIL, 1940).

Essas medidas são aplicadas aos inimputáveis e semi-imputáveis, com indicação de internação em Hospital de Custódia e Tratamento Psiquiátrico (HCTP) ou sujeição a tratamento ambulatorial. As pessoas com sofrimento mental são consideradas inimputáveis, quando, ao cometer o delito, são incapazes de entender a ilicitude do fato e de determinar-se de acordo com esse entendimento. Já os semi-imputáveis são aqueles que, embora aparentemente sãos, não têm plena capacidade de entender o caráter ilícito do fato ou de determinar-se conforme esse entendimento (BRASIL, 1940). Sendo assim, os inimputáveis são custodiados pelo Estado, que visa, através 
das medidas de segurança, proteção especial sobre o indivíduo e prevenção geral sobre a sociedade (BRASIL, 1940).

Em 2011, sob demanda do Departamento Penitenciário Nacional, foi realizado o primeiro censo no país para mapear os estabelecimentos e as pessoas que recebiam tratamento psiquiátrico obrigatório em cumprimento de uma medida de segurança (DINIZ, 2013). Pôde-se, então, conhecer o número de Estabelecimentos de Custódia e Tratamento Psiquiátrico (ECTP) existentes, bem como a sua localização e demais características. De acordo com essa contagem, existe um total de 26 ECTPs, sendo 23 HCTPs e 3 Alas de Tratamento Psiquiátrico (ATP) (DINIZ, 2013).

Todos os ECTPs permaneceram ligados aos sistemas de segurança e, apesar de serem chamados "hospitais", foram incorporados ao sistema penitenciário e não ao sistema de saúde, sendo inicialmente regidos apenas segundo os princípios da execução penal a partir da Lei no 7.210, de 1984 (JACOBINA, 2008). A Procuradoria Federal dos Direitos do Cidadão do Ministério Público Federal (PFDC/MPF), no ano de 2008, através do workshop "Saúde Mental e Reforma Psiquiátrica”, enfatizou a situação de que os pacientes em cumprimento de medida de segurança eram acompanhados apenas pelos órgãos do sistema penitenciário e considerou que a Lei da Reforma Psiquiátrica alterou a Lei no 7.210 , de 1984, e o CP no que se refere à medida de segurança (BRASIL, 2011a).

A discussão também foi evidenciada no seminário "Justiça e Saúde Mental" promovido no ano de 2009, no qual usuários, familiares e representantes de organizaçóes civis dos serviços de saúde mental produziram um documento que foi entregue ao Ministério Público com diversas reivindicaçôes, objetivando a promoção de melhor assistência a esses indivíduos (BRASIL, 2011a). Em abril de 2010, foi promulgada pelo Conselho Nacional de Justiça a resolução no 113 que incluiu a Lei da Reforma Psiquiátrica no regimento do processo de aplicação da medida de segurança, juntamente com a lei da execução penal (BRASIL, 2010).

Ainda em 2010, a resoluçáo no 4, de 30 de julho, do Conselho Nacional de Política Criminal e Penitenciária enfatizou a necessidade da observação dos princípios estabelecidos pela Lei no 10.216/2001 na execução da medida de segurança e propôs orientaçóes importantes, como a abordagem intersetorial, o acompanhamento psicossocial contínuo, a individualização da medida imposta, com respeito às singularidades psíquicas, sociais e biológicas de cada um, a inserção social, entre 
outros. A mesma resolução apontou o Programa de Atenção ao Paciente Judiciário como o responsável em articular de forma permanente com a rede pública de saúde e a rede social, visando a individualização do projeto de atenção integral e à promoção social do paciente, com a efetivação das políticas públicas cabíveis ao caso (BRASIL, 2010a). Em seu artigo sexto, definiu um prazo de dez anos para a substituição do modelo de cumprimento de medida de segurança em caráter manicomial para o modelo antimanicomial (BRASIL, 2010a).

Considerando as circunstâncias expostas, este estudo objetiva elucidar as condiçôes de tratamentos recebidos por pessoas com sofrimento mental submetidas à medida de segurança em HCTPs ou em ATPs inspecionados pelo Mecanismo Nacional de Prevenção e Combate à Tortura (MNPCT), nos anos de 2015 e 2016, bem como discutir as distorçôes legais em relação ao preconizado pelo Ministério da Saúde e pela Lei no $10.216 / 01$.

\section{Métodos}

Trata-se de um estudo descritivo com abordagem qualitativa baseado nos relatórios de visitas a unidades de privação de liberdade realizadas pelo MNPCT em diferentes estados da federação brasileira nos anos de 2015 e 2016.

O MNPCT, órgão instituído pela Lei federal no 12.847/2013, promulgada a partir do compromisso estabelecido pelo Estado brasileiro após a ratificação do Protocolo Facultativo à Convenção contra a Tortura e outros Tratamentos ou Penas Cruéis, Desumanos ou Degradantes, ratificado em 2007, tem como função principal a prevenção e combate à tortura a partir de visitas regulares a pessoas privadas de liberdade (BRASIL, 2013). Pessoas privadas de liberdade são aquelas obrigadas, por ordem superior, a permanecerem em determinados locais públicos ou privados, dos quais estão proibidas de sair, independentemente de sua vontade, abrangendo, dentre outros, os hospitais psiquiátricos e as casas de custódia (BRASIL, 2013).

Conforme apresentado em seus relatórios, a metodologia utilizada pelo MNPCT durante as visitas foi construída com base em diretrizes internacionais e, em suma, consiste em observar, nos locais de privação de liberdade visitados, suas rotinas institucionais, equipamentos e estruturas. Ainda, durante as visitas, "busca-se entrevistar quatro tipos de atores: as pessoas privadas de liberdade; os agentes públicos com contato direto com essas pessoas (ex.: agentes penitenciários, educadores ou 
cuidadores); profissionais de áreas técnicas (ex.: saúde, assistência social ou educação); e a direção da unidade. As entrevistas são realizadas de modo reservado. Ademais, são coletadas normas internas, protocolos de procedimentos institucionais, os documentos individuais pertinentes, dentre outros" (MNCTP, 2017, p. 10).

Após cada visita, o MNPCT tem a competência de elaborar um relatório circunstanciado e deve apresentá-lo a autoridades elencadas em lei. Nesse sentido, os relatórios referentes às visitas são construídos a partir da triangulação de informaçōes, por meio de quatro procedimentos principais: “(i) entre diferentes segmentos (ex.: situaçóes narradas igualmente por pessoas privadas de liberdade, por agentes técnicos e pela direção); (ii) por quantitativo dentro do mesmo segmento (ex.: afirmação de muitas pessoas privadas de liberdade), ou ainda por saturação de informação; (iii) por distribuição espacial de segmento (ex.: alegaçóes de indivíduos em diferentes pavilhôes, alas ou módulos); e (iv) por confrontação documental (ex.: situações mencionadas e procedimentos documentados)" (MNCTP, 2017, p. 10). Esses relatórios são digitalizados e disponibilizados publicamente em formato PDF na página oficial da Secretaria de Direitos Humanos (SDH).

Para a construção do presente estudo, foram incluídos todos os relatórios publicados até o mês de janeiro de 2017, que abordavam o resultado de inspeçôes realizadas em HCTPs ou em ATPs. Os demais relatórios, que abrangiam visitas a unidades de privação de qualquer outra natureza, foram excluídos.

Os relatórios inquiridos foram avaliados segundo os parâmetros descritos, sendo os resultados exibidos e discutidos de acordo com a política nacional de saúde mental. Por se tratar de pesquisa documental com acesso a dados disponibilizados publicamente, não foi necessária a avaliação do Comitê de Ética em Pesquisa.

\section{Resultados}

Foram encontrados 22 relatórios de visitas a unidades com restrição de liberdade publicados entre julho de 2015 e outubro de 2016 e disponibilizados no site da SDH do Ministério dos Direitos Humanos. Esses relatórios eram referentes a visitas realizadas a 53 diferentes unidades localizadas nos estados do Amazonas, Ceará, Distrito Federal, Maranhão, Mato Grosso do Sul, Pará, Paraíba, Pernambuco, Rio Grande do Sul, Rondônia, Santa Catarina e São Paulo. Durante esse período, as unidades investigadas englobaram aquelas referentes ao sistema prisional, sistema 
socioeducativo e de saúde mental, que possuíam em comum o fato de abrigarem pessoas cerceadas de sua liberdade.

O principal critério considerado pelo MNPCT para a escolha dos estados e locais a ser visitados foi a garantia de açôes em diferentes regióes, impedindo que ficassem restritas a uma única localidade ou estado. Dados oficiais, denúncias registradas por órgãos federais ou a subnotificação de tortura também foram usados como fontes de informaçóes para a escolha das unidades federativas. Após a definiçấo do estado a ser visitado, o próximo passo foi observar o cenário local e definir os tipos de espaços de privação de liberdade que seriam analisados. Esta etapa foi executada juntamente com organizaçôes locais da sociedade civil e atores estratégicos do poder público, que disponibilizaram informaçôes sobre os espaços de privação de liberdade mais problemáticos, com maior incidência de violações de direitos humanos (MNCPT, 2016).

Com aproximadamente um mês de antecedência, o MNPCT oficiava o período de sua ida às instituiçôes do poder público e da sociedade civil local, sem especificar quais os espaços de privação de liberdade seriam visitados, de forma a garantir que as visitas ocorressem de maneira inesperada. $\mathrm{O}$ tempo de permanência médio das visitas foi de cinco dias e a equipe era composta, em média, por quatro pessoas. Quando pertinente, eram convidados outros profissionais especialistas ou representantes da sociedade civil para acompanhá-los.

As visitas começavam com uma conversa com a direção da unidade, informando sobre a atuação do órgão prevista em lei. Posteriormente, as pessoas privadas de liberdade e os profissionais da unidade foram entrevistados, por intermédio de conversas coletivas ou individuais. Durante toda a visita, foram observadas as estruturas do local, feitos registros fotográficos e analisadas as documentaçóes institucionais. Finalmente, realizava-se uma segunda conversa com a direção, na qual eram apontados os próximos passos do trabalho do MNPCT e quais situaçóes precisariam ser resolvidas de imediato (MNCPT, 2016).

Em até trinta dias após as visitas, os relatórios finais com as recomendaçôes foram entregues às autoridades competentes, expondo as condiçôes gerais das unidades visitadas, bem como as normas, rotinas e práticas desenvolvidas que propiciavam a tortura e maus-tratos. Casos particulares de tortura encontrados durante as visitas foram preservados, visando assegurar a privacidade da vítima, a confidencialidade 
das informaçôes e a prevenção de represálias. Casos individuais foram encaminhados ao Ministério Público e Poder Judiciário, bem como a outros órgãos fiscalizadores competentes, para a devida apuração e encaminhamento (MNCPT, 2016). Apesar de avaliarem os mesmos parâmetros, não houve padronização em relação à forma de estruturação escrita de cada relatório.

Dos 22 relatórios divulgados pelo MNPCT, apenas cinco se referiam a visitas realizadas em HCTPs ou em ATPs. As unidades de saúde mental visitadas pelo MNPCT correspondem a 19,2\% daquelas existentes no país (Figura 1) e estão localizadas nos estados do Pará, Paraíba, Rio Grande do Sul, Rondônia e São Paulo (Tabela 1).

Figura 1. Distribuição dos Estabelecimentos de Custódia e Tratamento Psiquiátrico em território nacional com ênfase nos que foram visitados pelo Mecanismo Nacional de Prevenção e Combate à Tortura

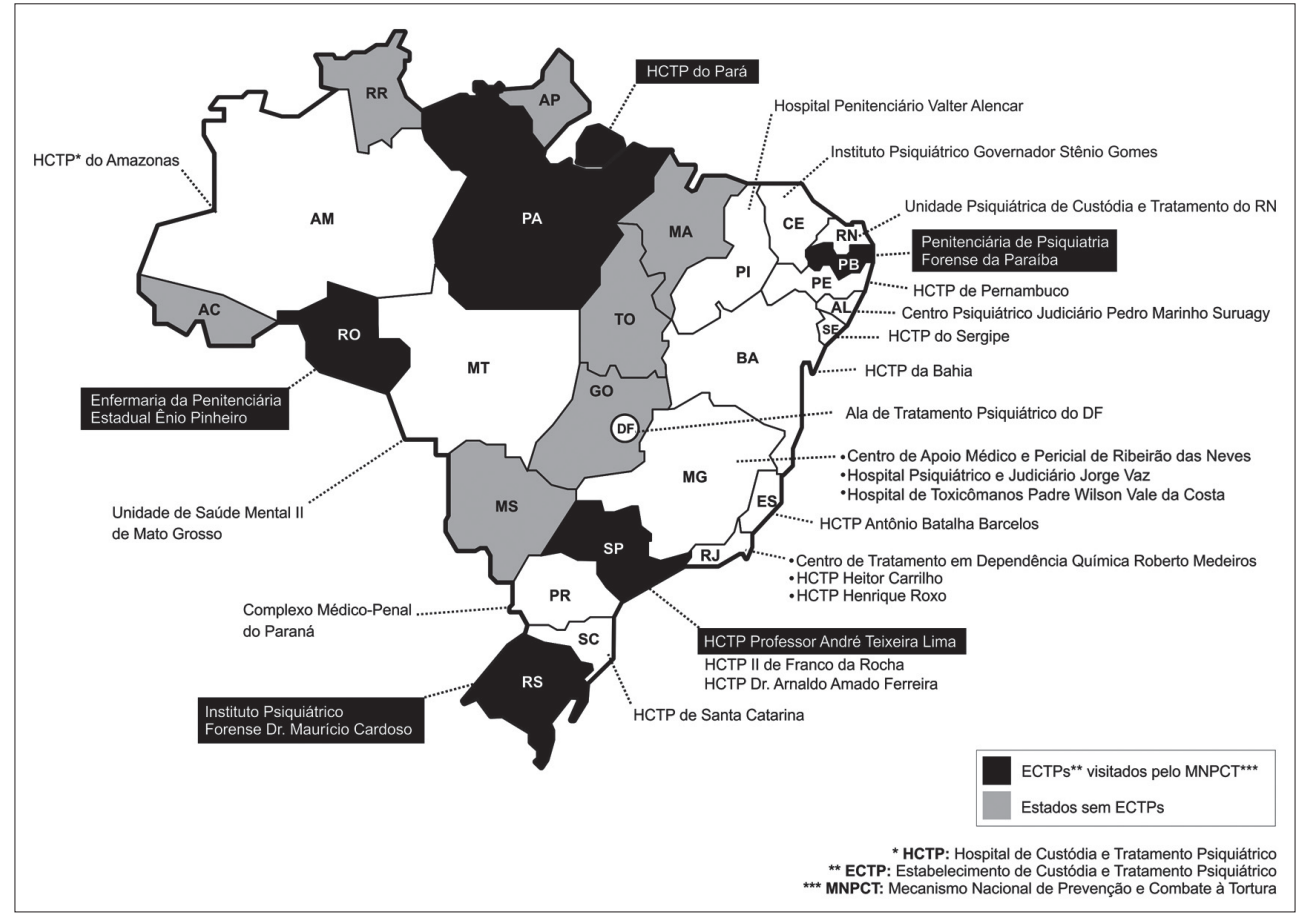

Fonte: Dados secundários retirados do Censo 2011 (DINIZ, 2013). 
Tabela 1. Estabelecimentos de Custódia e Tratamento Psiquiátrico visitados pelo Mecanismo Nacional de Prevençâo e Combate à Tortura entre os anos de 2015 e 2016

\begin{tabular}{lll}
\hline Estado & Unidade de Saúde Mental & Período \\
\hline Pará & $\begin{array}{l}\text { Hospital de Custódia e Tratamento Psiquiátrico do } \\
\text { Pará }\end{array}$ & Junho 2016 \\
Paraíba & Penitenciária de Psiquiatria Forense da Paraíba & $\begin{array}{l}\text { Agosto/ } \\
\text { Setembro 2016 }\end{array}$ \\
Rio Grande do Sul & Instituto Psiquiátrico Forense Mauricio Cardoso & Outubro 2015 \\
Rondônia & $\begin{array}{l}\text { Enfermaria psiquiátrica do Hospital de Base Ary } \\
\text { Pinheiro }\end{array}$ & Agosto 2016 \\
& Hospital de Custódia e Tratamento Psiquiátrico & Setembro 2015 \\
& Prof. André Teixeira de Lima & \\
\hline
\end{tabular}

\section{Discussão}

O Hospital de Custódia e Tratamento Psiquiátrico, antigo manicômio judiciário, é o local para o qual são enviadas as pessoas com transtorno mental que cometeram algum delito. Após constatada a sua inimputabilidade mediante o exame de sanidade mental, esses são confinados nesses locais para o recebimento de tratamento adequado, cumprindo a medida de segurança imposta a partir da decisão judicial (MISSAGGIA, 2010).

Mais de $90 \%$ dos pacientes periciados recebem o diagnóstico de doença mental e a maioria absoluta recebe como sanção a medida de segurança cumprida sob internação, que visa ao tratamento e à reintegraçáo social desses indivíduos, sendo fundamental que haja apoio interdisciplinar de equipes terapêuticas (DIMARE, 2010).

Diferentemente dos inimputáveis, os indivíduos considerados mentalmente sãos e desenvolvidos, capazes de entender o caráter ilícito do fato e de determinar-se de acordo com esse entendimento, são considerados imputáveis e, segundo a lei, estáo sujeitos ao cumprimento de pena (BRASIL, 1940). Para Queiroz (2008), apesar de pena e medida de segurança terem significados judicialmente distintos, não há distinção alguma quando consideradas em sua essência. Ambas possuem os mesmos fins e implicam idênticos pressupostos de punibilidade. Atendendo-se a critério de pura conveniência político-criminal, acredita que a distinção reside, unicamente, nas consequências: os imputáveis estáo sujeitos à pena, os inimputáveis, à medida de segurança. 
Assim sendo, tanto a pena como a medida de segurança têm como finalidade reabilitar o indivíduo ao convívio social, bem como prevenir novas práticas ilícitas (MIRABETE; FABBRINI, 2007; DIMARE, 2010). A diferença está na abordagem e nas estratégias utilizadas por cada uma para o alcance do objetivo final, sendo que os indivíduos inimputáveis são passíveis de receber tratamento específico para a sua condição, direito este garantido por lei.

Por isso, o HCTP é considerado uma instituição dual: hospital e presídio. Como hospital, existem os profissionais destinados a "tratar" os pacientes até a sua "recuperação". Como prisão, existem os agentes penitenciários que prezam pela ordem local. Parte hospital e parte prisão, reflete os embates entre a medicina e o direito (CARRARA, 1998). Ao englobar conceitos dos dois domínios, cria-se um limite médico-jurídico marcado pelo predomínio de propostas essencialmente determinadas pelo direito. Por conseguinte, as abordagens psiquiátrica e jurídica ainda necessitam de uma maior aproximação no intuito de proporcionar um trabalho mais integrado e de melhor qualidade (ABDALLA-FILHO; ENGELHARDT, 2003). Santos et al. (2015) reforçam essa ideia ao considerar que as abordagens do direito e da saúde mental, apesar de se entrecruzarem, convergem para planos diferentes.

Isto posto, evidencia-se o limite do presente trabalho: preparado por profissionais da área da saúde, destaca a assistência aos indivíduos em cumprimento de medida de segurança do ponto de vista da saúde mental, levando em conta os direitos das pessoas com transtornos mentais e as propostas de modelo de atenção psicossocial em vigência no país (BRASIL, 2001; BRASIL, 2011), estando, por isso, suscetível a distanciar-se da área jurídica.

Um exemplo da lacuna existente entre as abordagens psiquiátrica e jurídica está nas divergências entre a classificação dos doentes mentais realizada pela psiquiatria forense e pela clínica. Segundo Taborda et al. (2016), a expressão Transtorno Mental é utilizada pela Organização Mundial da Saúde (OMS) e pela Associação Americana de Psiquiatria em seus sistemas de classificação dos transtornos mentais, no entanto não é utilizada pelo $\mathrm{CP}$, que prevê quatro categorias para englobar a expressão: doença mental, perturbação da saúde mental, desenvolvimento mental incompleto e desenvolvimento mental retardado.

Assim sendo, no contexto do CP, o termo doença mental compreende as psicoses e os transtornos neurocognitivos maiores, referindo-se a estados em que haja algum grau de alienação mental e comprometimento do juízo de realidade. $\mathrm{O}$ termo 
perturbação da saúde mental abarca os transtornos da personalidade, as parafilias e as neuroses. Já o desenvolvimento mental incompleto faz referência à deficiência mental, oligofrenia ou deficiência intelectual (retardo mental), englobando níveis de acometimento de diferentes intensidades. Para esses sujeitos, é considerado mais importante investigar se as capacidades de entendimento e autodeterminação foram comprometidas pela deficiência intelectual e se houve nexo de causalidade, ou seja, se o ato cometido adveio do transtorno mental (TABORDA et al., 2016).

Por último, tem-se o termo desenvolvimento mental retardado, praticamente não mais empregado, uma vez que se trata de indivíduos nos quais embora não haja transtorno mental, pode haver o comprometimento de sua capacidade de entendimento ou de determinação, remontando a 1940, quando predominavamse hábitos culturais locais e leis particulares, sendo a maior parte da população analfabeta. A categoria compreende entâo silvícolas não adaptados, surdos-mudos com a capacidade de comunicação comprometida, e outras pessoas com grau extremo de primitivismo, que apresentariam desempenho próximo ao das pessoas com deficiência intelectual (TABORDA et al., 2016).

Em consequência dessa categorização proposta pelo $\mathrm{CP}$, o diagnóstico clínico realizado a partir de uma perícia criminal e classificado segundo a CID-10 (classificação proposta pela OMS e adotada no Brasil), deve ao final ser convertido às terminologias jurídicas supracitadas, buscando o estabelecimento de uma correta conexão entre os dois campos. Porém, ao converter a linguagem do domínio psiquiátrico em termos jurídicos, o diagnóstico clínico pode ser desvalorizado no intuito de gerar uma definição legal (TABORDA et al., 2016).

Sabe-se que para a instituição correta do tratamento, é necessário analisar, de forma precisa, o enquadramento jurídico de cada doente mental e sua compatibilidade com a clínica apresentada, de forma a não ocasionar prejuízos aos mesmos. Porém, muitas vezes os transtornos e doenças mentais juntamente com os seus subtipos não são analisados no momento da aplicação da medida de segurança, já que o exame psiquiátrico forense apresenta como resultado estritamente uma conclusão médico-legal, não havendo proposta terapêutica para a patologia em questão (TABORDA; BINS, 2016).

Essa abordagem predispóe à adoção de tratamentos homogeneizantes para internos com diferentes perfis, como foi observado nos relatórios analisados. 
Exemplificando, tem-se a aplicação de tratamentos semelhantes para portadores de dependência química e psicopatia (MNPCT, 2015; 2015a; 2016a; 2016b; 2016c).

Em 2014, o Ministério da Saúde estabeleceu, através das Portarias no 94 e no 95 , a instituição do serviço de avaliação e acompanhamento de medidas terapêuticas aplicáveis à pessoa com transtorno mental em conflito com a lei, composto pela Equipe de Avaliação e Acompanhamento das Medidas Terapêuticas Aplicáveis à Pessoa com Transtorno Mental em Conflito com a Lei, cujo objetivo é, entre outros, a articulação com a rede de atençâo à saúde na implementação de açôes e serviços que beneficiem essa população, como a construção do Projeto Terapêutico Singular (PTS), o acompanhamento integral e contínuo da execução de medidas terapêuticas, assim como a realização da desinternação progressiva dessas pessoas, usando-se de dispositivos oferecidos pelas redes de atenção à saúde, assistência social e outros programas e serviços de direitos de cidadania (BRASIL, 2014; 2014a).

Assim, do ponto de vista da saúde mental, cada pessoa com sofrimento psíquico deve receber tratamento individualizado voltado para sua condição e por isso se faz imperiosa a construção do PTS, que possibilita uma prática compartilhada entre o indivíduo, seu técnico de referência e demais profissionais de acordo com as suas necessidades e demandas (GRIGOLO et al., 2015).

O profissional de referência torna-se responsável pela construção e avaliação constante do PTS juntamente com o usuário e sua família, sempre que possível e necessário, além de acompanhar e fazer a mediaçáo do percurso terapêutico do usuário nos pontos de atenção da rede de saúde e de outros setores, envolvendo equipes de referência e de apoio (GRIGOLO et al., 2015). As inspeçôes aos HCTPs relataram ausência de atividade que envolvesse os internos na construção de um projeto de tratamento e de cidadania, sendo reservado a esses apenas o uso da medicação imposta, desconsiderando as particularidades de cada um (MNPCT, 2015; 2015a; 2016a; 2016b; 2016c).

A ausência de PTS difere dos objetivos da medida de segurança, visto que o seu estabelecimento permite a instituição da terapêutica individualizada e possibilita a programação do processo de desinstitucionalização, que deve ser entendido não apenas como a desospitalização, mas como um processo complexo, que possibilite a sua reinserção social ao mesmo tempo que lhe seja garantida a inclusão na Rede de Atenção Psicossocial (RAPS). 
Em algumas instituiçôes foi constatada a manutenção de internos que já tinham suas medidas de segurança extintas. Em todos os casos náo houve interlocução com a RAPS de forma sólida e articulada (MNPCT, 2015; 2015a; 2016a; 2016b; 2016c).

Ademais, ressalta-se a recomendação de que a elaboração do PTS envolvesse, sempre que possível, além da própria pessoa em conflito com a lei, seus familiares ou outras pessoas de sua referência social, visando à correponsabilização no cuidado e a articulação em rede das condutas terapêuticas (BRASIL, 2014).

Dessa forma, prevê-se o contato com os familiares, fundamental para vinculá-los ao tratamento e à responsabilidade com os doentes e diminuir os riscos de abandono (DIMARE, 2010). Nesse contexto, nos HCTPs visitados, embora a permissão para o recebimento de visitas ocorresse em média duas vezes por semana, muitas famílias eram do interior do estado e, devido a isso, os relatórios enfatizam que a internação na capital aprofunda a desconstrução dos vínculos sociofamiliares (MNPCT, 2015; 2015a; 2016a; 2016b; 2016c).

Também foi unânime a negação da garantia da visita íntima, importante para a manutenção desses vínculos afetivos e familiares. $\mathrm{Na}$ verdade, familiares, amigos ou qualquer outra pessoa que mantinham vínculo afetivo com os internos não participavam das atividades institucionais, contribuindo para o enfraquecimento dos laços sociais entre as pessoas privadas de liberdade e o mundo externo (MNPCT, 2015; 2015a; 2016a; 2016b; 2016c).

No Brasil, existem relatos da experiência de dois programas que integram o paciente judiciário com sofrimento mental à rede pública de saúde e à rede de assistência social: o Projeto de Acompanhamento Interdisciplinar ao Paciente Judiciário, em Minas Gerais, e o Programa de Atenção Integral ao Louco Infrator, em Goiás. Esses programas atuam de modo intersetorial, através de parcerias entre o Judiciário, o Executivo e a comunidade, promovendo, de forma geral, a atenção integral à pessoa com transtorno mental e, ainda que existam algumas limitaçóes, poderiam servir como modelo para o desenvolvimento de novos projetos em outros estados (BARROS-BRISSET, 2010; SILVA, 2010).

Apesar disso, Jacobina (2008) observa que, em geral, há a prevalência da perspectiva punitiva sobre a do cuidado, ainda que os HCTPs sejam uma instituição ambígua. Assim, fazem parte do cuidado em saúde mental, além da integração familiar e do tratamento medicamentoso quando indicado, intervençôes que promovam a qualidade de vida, sendo necessária a observação do sujeito em suas diversas dimensôes, 
com seus desejos, anseios, valores e escolhas, promovendo a atenção ao indivíduo de maneira integral e compartilhada (BRASIL, 2013a). Para isso, é fundamental a garantia de condiçôes básicas de infraestrutura e uma rotina institucional composta de atividades inclusivas, como intervençôes psicoeducacionais individuais, grupos operativos e atividades de lazer e trabalho (BRASIL, 2013a). Todavia, os relatórios publicados pelo MNPCT denunciam condiçôes de infraestrutura incompatíveis com as propostas de tratamento (MNPCT, 2015; 2015a; 2016a; 2016b; 2016c).

Mesmo em instituiçóes localizadas em diferentes regiôes, os relatos apontaram realidades semelhantes: foram encontradas configuraçóes de aprisionamento, superlotaçáo do ambiente, violência constante, privação do acesso à assistência jurídica, ausência de acesso à saúde, condiçôes de higiene e infraestrutura precárias e a não integração à RAPS (MNPCT, 2015; 2015a; 2016a; 2016b; 2016c).

Em relação à infraestrutura básica, foi constatada situação de insalubridade: ausência de colchóes para todos os internos, corredores escuros, sujos e malcheirosos, pouco ou nenhum acesso à água potável para consumo e falta de chuveiro para banho em muitas celas. Ademais, observou-se escassez de material de higiene, ausência de vaso sanitário na maioria das celas, vazamentos, paredes com infiltraçóes, entupimento de encanamentos, mofo, pintura gasta, iluminação inadequada e pouco arejamento. Em muitos deles havia grades nas portas e janelas e os banheiros não possuíam portas. Também houve relato de ausência de iluminação elétrica em um dos locais, onde as pessoas eram mantidas no escuro com a chegada da noite. Observou-se ainda convívio de internos diretamente com roedores e insetos. A alimentação, quando relatada, foi tida como insuficiente e sem qualidade, muitas vezes chegando estragada às celas (MNPCT, 2015; 2015a; 2016a; 2016b; 2016c).

Muitos dos indivíduos usavam roupas sujas e tinham mau cheiro. Além disso, em alguns hospitais as funçôes de limpeza ficavam a cargo dos próprios internos. Em todos os locais visitados, os internos eram privados de atividades dignas de trabalho, educação, terapia ocupacional e lazer, à exceção do acesso a atividades de manicure e costura por parte de algumas internas e atividades de jardinagem para os internos do HCTP visitado em São Paulo; e a existência, na Paraíba, de assistência religiosa pelas Pastorais Evangélica, Católica e Espírita, além de atividades de educação física, o uso de um pequeno campo de futebol para lazer e a disponibilidade de um saláo para corte de cabelo (MNPCT, 2015; 2015a; 2016a; 2016b; 2016c). 
Outra prática constatada pelos relatórios foi o uso da contenção e castigo. Em momentos de crise, em Rondônia, a contenção era realizada pelos agentes prisionais, sem o cumprimento de qualquer protocolo. Os indivíduos eram algemados e conduzidos por meio do uso da força para um espaço com características de prisão ou isolamento (MNPCT, 2016c). No HCTP de São Paulo, havia a presença majoritária de agentes de segurança penitenciária convivendo com os pacientes, exercendo também condutas do sistema prisional. Nesse caso, apesar de haver protocolo de contenção, este não era seguido, uma vez que a contenção era escolhida como primeira intervenção e usada também em situaçôes que envolviam questôes disciplinares, perdendo o seu caráter terapêutico. Nesse local, inúmeras denúncias foram registradas, de agressôes verbais até espancamentos (MNPCT, 2015).

No Pará, os depósitos de materiais de limpeza, salas minúsculas e sem ventilação, eram usados para prática de tortura. Os internos eram levados a esses locais como forma de castigo, ficavam algemados com um tempo médio de confinamento de 10 a 20 dias. Suas necessidades fisiológicas eram realizadas sem distinção do espaço de confinamento. Não havia acesso à justiça, nem um canal imparcial e seguro para o registro de denúncias. Os internos permaneciam à mercê desses tratamentos sem a possibilidade de nenhuma providência (MNPCT, 2016b). Adicionalmente, não havia garantia de banho de sol diário e os internos eram submetidos à medicação em quantidade excessiva como uma maneira de "neutralizar" as dores vivenciadas e de disciplinar o comportamento (MNPCT, 2016b).

O uso de técnicas de natureza coercitiva/punitiva acompanha a história da psiquiatria. Por contenção física entende-se a imobilização do paciente contra o solo realizada por diversas pessoas da equipe, a contenção mecânica refere-se ao uso de faixas de couro ou tecido para fixar o paciente ao leito, e por isolamento entende-se a manutenção do paciente em um quarto fechado, ou seja, o mesmo fica impossibilitado de sair, mas não se encontra preso a nenhuma superfície (MANTOVANI et al., 2010).

O grau de agitação e agressividade do paciente pode representar risco para si mesmo e para as pessoas que estão em seu entorno, como outros pacientes e profissionais. Nesses casos, se as intervençôes verbais, não verbais e medicamentosas não forem suficientes para o controle da situação, pode ser indicado o uso de técnicas de contenção ou isolamento (MANTOVANI et al., 2010). 
Segundo Mantovani et al. (2010), no Brasil não há normatizaçôes legais que abordem as práticas de isolamento e contenção, nem que determinem se sua realização constitui ou não em ato médico. $\mathrm{Na}$ prática, a decisão da utilização ou não de contenção mecânica baseia-se no julgamento clínico, porém é importante ressaltar que, apesar de nem sempre as instituiçóes disporem de protocolos específicos, a contenção mecânica quando não aplicada de forma criteriosa pode levar a complicaçôes graves, como redução da perfusão em extremidades, desidratação, depressão respiratória, fraturas e até mesmo morte súbita, além do trauma psicológico envolvido (MANTOVANI et al., 2010).

Por todas as inadequaçóes ainda vigentes no contexto dos HCTPs, o "Parecer sobre medida de segurança e hospital de custódia e tratamento psiquiátrico sob a perspectiva da Lei no 10.216/2001", publicado em 2011 pela PFDC e pelo MPF, enfatiza que as autoridades federais e estaduais, ao manterem em funcionamento esse dispositivo disciplinar, estão violando a Lei no 10.216/2001. Esse parecer coloca como premente a extinçáo dos HCTPs, com o redirecionamento de todos os recursos federais e estaduais utilizados em sua manutenção para a implementação e expansão dos inúmeros dispositivos da RAPS (BRASIL, 2011a).

Para os mesmos autores, a área da saúde, em esfera estadual e municipal, deve assumir a responsabilidade pelo projeto e pela gestão, de acordo com suas atribuiçôes legislativas. Eles entendem que "o paciente em medida de segurança é sujeito da saúde e não da justiça" (BRASIL, 2011a; p. 85). Para a viabilidade dessa complexa mudança, é preciso que tanto a justiça quanto a saúde entendam a proposta e aceitem tal readequação (BRASIL, 2011a).

Por fim, Mattos (2006) considera que a aplicação das medidas de segurança representa exclusão e segregação em forma de tratamento e propóe a sua extinção. Acredita que a solução está na prevenção, já que relata que a pessoa com sofrimento mental tem a especificidade de produzir sinais claros de aviso antes de passar ao ato, o que mais uma vez salienta a necessidade de inclusão e acompanhamento desses doentes na rede de assistência à saúde mental. Reproduzem-se aqui suas indagaçóes, que, mesmo passados onze anos de sua publicação, são ainda inteiramente pertinentes: "O que produzem as medidas de segurança senão mais exclusão? Não seria 'menos ruim' a responsabilizaçáo do portador de sofrimento mental infrator? Por que a manutenção do binômio punição e tratamento, se apenas se estabelece a punição e a custódia para sempre?" (MATTOS, 2006, p. 148). 


\section{Conclusão}

Ao analisar os dados apresentados pelos relatórios, observa-se que todas as instituiçôes visitadas apresentaram características asilares, contrariando a Lei $\mathrm{n}^{\mathrm{o}}$ 10.2016/2001 e representando violaçôes aos direitos humanos.

Dessa forma, passados quase vinte anos da aprovação da Lei Antimanicomial, ainda são muitos os desafios e contradiçôes a serem transpostos, entre eles encontrase o impasse fronteiriço entre os domínios do direito e da saúde na garantia de tratamento adequado, com a construção do PTS e estratégias de desinstuticionalização progressiva, permitindo à pessoa com sofrimento psíquico a reinserção social e inclusão na rede de assistência em saúde mental, beneficiando-se do atendimento matricial. Não só a saúde e o direito, como também a economia e a política devem se conscientizar do exercício de suas atividades no contexto da Lei no 10.2016, de 2001.

Torna-se oportuno repensar os papéis de cada um na melhoria da prestação de serviços de saúde mental, permitindo a integração entre os HCTPs e a rede assistencial, de forma a adequar o padrão atual de funcionamento desses hospitais. É necessário garantir a efetivação dos direitos e justiça, buscando assegurar o respeito à dignidade das pessoas com sofrimento mental autores de delitos, conferindo a eles os direitos individuais previstos pela Constituição,de 1988.

O cenário encontrado sugere que estamos andando na contramão e, percorrendo um caminho contrário ao preconizado, questiona-se o surgimento do efeito indesejado. Quais serão as sequelas geradas por essas práticas? Ao invés de tratar, não estaríamos favorecendo e fomentando o agravamento de suas condiçóes de saúde?!

\section{Referências}

ABDALLA-FILHO, E.; ENGELHARDT, W. A prática da psiquiatria forense na Inglaterra e no Brasil: uma breve comparação. Revista Brasileira de Psiquiatria, v. 25, n. 4, p. 245-248, 2003. Disponível em: <http://dx.doi.org/10.1590/S1516-44462003000400012>. Acesso em: 2 fev. 2017. AMARANTE, P. Reforma Psiquiátrica e Epistemologia. Cadernos Brasileiros de Saúde Mental, v. 1, n. 1, 2009. Disponível em: <http://stat.ijkem.incubadora.ufsc.br/index.php/cbsm/article/ view/998/1107>. Acesso em: 4 fev. 2017.

BARROS-BRISSET, F. O. Um dispositivo conector: relato da experiência do PAI-PJ/TJMG, uma Política de Atençáo Integral ao louco infrator, em Belo Horizonte. Revista Brasileira de Crescimento e Desenvolvimento Humano, v. 20, n. 1, p. 116-128, 2010. Disponível em: <http:// pepsic.bvsalud.org/pdf/rbcdh/v20n1/16.pdf>. Acesso em: 3 fev. 2017. 
BRASIL. Código Penal. Decreto-Lei 2.848, de 7 de dezembro de 1940 alterado pela Lei no 9.777 em 26/12/98. Diário Oficial da União. Rio de Janeiro, 31 dez. 1940. Disponível em: <http://legis. senado.gov.br/legislacao/ListaPublicacoes.action?id=102343>. Acesso em: 3 fev. 2017.

- Constituição da República Federativa do Brasil de 1988. Promulgada em 5 de outubro de 1988. Disponível em <http://www.planalto.gov.br/ccivil_03/constituicao/ constituicaocompilado.htm>. Acesso em: 3 fev. 2017.

Lei no 10.216 , de 6 de abril de 2001. Dispóe sobre a proteção e os direitos das pessoas portadoras de transtornos mentais e redireciona o modelo assistencial em saúde mental. Diário Oficial da União. Brasília, DF, 9 abr. 2001. Seção 1. Disponível em: <http://www.planalto.gov. br/ccivil_03/leis/leis_2001/110216.htm>. Acesso em: 1 fev. 2017.

. Lei no 10.708 , de 31 de julho de 2003. Institui o auxílio-reabilitação psicossocial para pacientes acometidos de transtornos mentais egressos de internaçóes. Diário Oficial da União. Brasília, DF, 1 ago. 2003. Disponível em: < http://www.planalto.gov.br/ccivil_03/Leis/2003/ L10.708.htm>. Acesso em: 3 fev. 2017.

. Conselho Nacional de Justiça. Resolução no 113, de 20 de abril de 2010. Dispóe sobre o procedimento relativo à execuçáo de pena privativa de liberdade e de medida de segurança, e dá outras providências. Diário da Justiça Eletrônico, no 73, p. 3-7, 26 de abril de 2010. Disponível em: <http://www.cnj.jus.br/images/stories/docs_cnj/resolucao/rescnj_113. pdf>. Acesso em: 2 fev. 2017.

. Conselho Nacional de Política Criminal e Penitenciária. Resolução no 4, de 30 de julho de 2010. Dispóe sobre as Diretrizes Nacionais de Atenção aos Pacientes Judiciários e Execução da Medida de Segurança. Diário Oficial da União, seção 1, p. 38, 2 de agosto de 2010a. Disponível em: <https://www.justica.gov.br/seus-direitos/politica-penal/cnpcp-1/ resolucoes/resolucoes-arquivos-pdf-de-1980-a-2015/resolucao-no-4-de-30-de-julho-de-2010. pdf>. Acesso em: 2 fev. 2017.

. Ministério da Saúde. Portaria no 3.088, de 23 de dezembro de 2011. Institui a Rede de Atenção Psicossocial para pessoas com sofrimento ou transtorno mental e com necessidades decorrentes do uso de crack, álcool e outras drogas, no âmbito do Sistema Único de Saúde. Diário Oficial da União. Brasília, 23 dez. 2011. Disponível em: <http://bvsms.saude.gov.br/bvs/ saudelegis/gm/2011/prt3088_23_12_2011_rep.html>. Acesso em: 2 fev. 2017.

. Ministério Público Federal. Procuradoria Federal dos Direitos do Cidadáo. Parecer sobre medidas de segurança e hospitais de custódia e tratamento psiquiátrico sob a perspectiva da lei n. 10.216/2001. Brasília: Ministério Público Federal. 2011a. Disponível em: <http://pfdc.pgr. mpf.mp.br/temas-de-atuacao/saude-mental/docs-publicacoes/parecer_medidas_seguranca_ web.pdf>. Acesso em: 2 fev. 2017. 
. Lei no 12.847, de 2 de agosto de 2013. Institui o Sistema Nacional de Prevenção e Combate à Tortura; cria o Comitê Nacional de Prevenção e Combate à Tortura e o Mecanismo Nacional de Prevenção e Combate à Tortura; e dá outras providências. Diário Oficial da União. Brasília, DF, 5 ago. 2013. Disponível em: <http://www.planalto.gov.br/ccivil_03/_Ato20112014/2013/Lei/L12847.htm>. Acesso em: 5 fev. 2017.

- Ministério da Saúde. Secretaria de Atenção à Saúde. Departamento de Atenção Básica. Saúde Mental. Cadernos de Atenção Básica, no 34. Brasília: Ministério da Saúde, 2013a. Disponível em: <http://189.28.128.100/dab/docs/portaldab/publicacoes/caderno_34.pdf>. Acesso em: 4 fev. 2017.

. Ministério da Saúde. Portaria no 94, de 14 de janeiro de 2014. Institui o serviço de avaliaçáo e acompanhamento de medidas terapêuticas aplicáveis à pessoa com transtorno mental em conflito com a Lei, no âmbito do Sistema Único de Saúde (SUS). Diário Oficial da União, Poder Executivo, Brasília, DF, 15 jan. 2014. Disponível em: <http://bvsms.saude.gov.br/ bvs/saudelegis/gm/2014/prt0094_14_01_2014.html>. Acesso em: 2 fev. 2017.

- Ministério da Saúde. Portaria no 95, de 14 de janeiro de 2014. Dispóe sobre o financiamento do serviço de avaliação e acompanhamento às medidas terapêuticas aplicáveis ao paciente judiciário, no âmbito do Sistema Único de Saúde (SUS). Diário Oficial da União, Poder Executivo, Brasília, DF, 15 jan. 2014a. Disponível em: <http://bvsms.saude.gov.br/bvs/ saudelegis/gm/2014/prt0095_14_01_2014.html>. Acesso em: 2 fev. 2017.

CARRARA, S. Crime e loucura: o aparecimento do manicômio judiciário na passagem do século. Rio de Janeiro: EdUERJ; São Paulo: EdUSP, 1998. 228p.

CHIAVERINI, D. H. (Org.) et al. Guia prático de matriciamento em saúde mental. Ministério da Saúde. Brasília: Centro de Estudo e Pesquisa em Saúde Coletiva, 2011. 236 p. Disponível em: <http://bvsms.saude.gov.br/bvs/publicacoes/guia_pratico_matriciamento_saudemental. pdf>. Acesso em: 2 fev. 2017.

DIMARE, R. Transtorno mental e medidas de segurança: uma análise médico-jurídica. 2010. $71 f$. Monografia. Departamento de Ciências Penais, Faculdade de Direito, Universidade Federal do Rio Grande do Sul, Porto Alegre, 2010. Disponível em: <http://hdl.handle.net/10183/27067>. Acesso em: 2 fev. 2017.

DINIZ, D. A custódia e o tratamento psiquiátrico no Brasil: Censo 2011. Brasília: Letras Livres: Editora Universidade de Brasília, 2013. 382 p.

FERRAZ, M. P. T. História da psiquiatria no Brasil- Um pouco de São Paulo: estudo de caso. São Paulo: Leitura Médica, 2016.

GRIGOLO, T. M. et al. O projeto terapêutico singular na clínica da atenção psicossocial. Cadernos Brasileiros de Saúde Mental, v. 7, n.15, p. 53-73, 2015. Disponível em: <http://incubadora. periodicos.ufsc.br/index.php/cbsm/article/viewFile/2951/4437>. Acesso em: 2 fev. 2017. 
JACOBINA, P. V. Direito penal da loucura: medida de segurança e reforma psiquiátrica. Brasília: ESMPU, 2008. 153 p.

MANTOVANI, C. et al. Manejo de paciente agitado ou agressivo. Revista Brasileira de Psiquiatria, v. 32, s. 2, p. 96-103, 2010. Disponível em: <http://dx.doi.org/10.1590/S151644462010000600006>. Acesso em: 2 fev. 2017.

MATTOS, V. Crime e psiquiatria: Uma saída - Preliminares para a desconstrução das medidas de segurança. Rio de Janeiro: Revan, 2006. 233 p.

MiRABETE, J. F.; FABBRINI, R. N. Manual de Direito Penal. 24 ed. São Paulo: Atlas, 2007. MISSAGGIA, R. O. Breves reflexões sobre medidas de segurança. Âmbito Jurídico. Rio Grande, XIII, n. 83, 2010. Disponível em: <http://www.ambito-juridico.com.br/site/?n_link=revista_ artigos_leitura\&artigo_id=8833\&revista_caderno=3>. Acesso em: 2 fev. 2017.

MNPCT. Relatório de visita ao Hospital de Custódia e Tratamento Psiquiátrico "Professor André Teixeira Lima": HCTP I - Franco da Rocha, São Paulo. Brasília, 2015. Disponível em: <http:// www.sdh.gov.br/sobre/participacao-social/comite-nacional-de-prevencao-e-combate-a-tortura/ representantes/hospital-de-custodia-e-tratamento-psiquiatrico-prof.-andre-teixeira-lima>. Acesso em: 20 jan. 2017.

- Relatório de visita ao Instituto Psiquiátrico Forense - Rio Grande do Sul. Brasília, 2015a. Disponível em: <http://www.sdh.gov.br/sobre/participacao-social/comite-nacional-deprevencao-e-combate-a-tortura/representantes/instituto-psiquiatrico-forense>. Acesso em: 20 jan. 2017.

Relatório Anual 2015-2016. Brasília, 2016. 92p. Disponível em: <http://www. sdh.gov.br/sobre/participacao-social/sistema-nacional-de-prevencao-e-combate-a-torturasnpct/mecanismo/mecanismo-nacional-de-prevencao-e-combate-a-tortura-relatorioanual-2015-2016>. Acesso em: 20 jan. 2017.

Relatório de visita a unidades de privação de liberdade no estado da Paraíba. Brasília, 2016a. Disponível em: <http://www.sdh.gov.br/sobre/participacao-social/sistema-nacional-deprevencao-e-combate-a-tortura-snpct/mecanismo/paraiba-relatorio-de-visita-as-unidades-deprivacao-de-liberdade-da-paraiba-outubro-2016-1>. Acesso em: 20 jan. 2017.

- Relatório de visita a unidades de privação de liberdade no estado do Pará. Brasília, 2016b. Disponível em: <http://www.sdh.gov.br/sobre/participacao-social/sistema-nacional-deprevencao-e-combate-a-tortura-snpct/mecanismo/relatorio-de-visita-as-unidades-de-privacaode-liberdade-do-para-julho-2016>. Acesso em: 20 jan. 2017.

- Relatório de visita a unidades de privação de liberdade no estado de Rondônia. Brasília, 2016c. Disponível em: <http://www.sdh.gov.br/sobre/participacao-social/sistema-nacional-deprevencao-e-combate-a-tortura-snpct/mecanismo/rondonia-relatorio-de-visita-as-unidades-deprivacao-de-liberdade-de-rondonia-outubro-2016>. Acesso em: 20 jan. 2017. 
. Relatório de missáo a unidades de privação de liberdade do estado do Mato Grosso. Brasília, 2017. Disponível em: <http://www.sdh.gov.br/sobre/participacao-social/sistema-nacional-deprevencao-e-combate-a-tortura-snpct/mecanismo/relatorio-mato-grosso-2017/>. Acesso em: 18 set. 2017.

ODA, A. M. G. R.; DALGALARRONDO, P. O início da assistência aos alienados no Brasil ou importância e necessidade de estudar a história da psiquiatria. Revista Latinoamericana de Psicopatologia Fundamental, VII, n. 1, p. 128-141, 2004. Disponível em: <http://dx.doi. org/10.1590/1415-47142004001012>. Acesso em: 1 fev. 2017.

PÊCEGO, A. J. F. S.; GERIAGE NETO, Z. Crack: internação compulsória e cidadania. Revista da AJURIS, v. 40, n. 130, p. 73-88, 2013. Disponível em: <http://www.ajuris.org.br/ OJS2/index.php/REVAJURIS/article/view/291>. Acesso em 18 set. 2017.

QUEIROZ, P. Penas e medidas de segurança se distinguem realmente?. Clubjus. Brasília-DF: 2 mar. 2008. Disponível em: <http://www.clubjus.com.br/?artigos\&ver=2.16167\&hl=no>. Acesso em: 5 fev. 2017.

SANTOS, A. L. G.; FARIAS, F. R.; PINTO, D. S. Por uma sociedade sem hospitais de custódia e tratamento psiquiátrico. História, Ciências, Saúde - Manguinhos, v. 21, n. 4, p. 1215-1230, 2015. Disponível em: <http://dx.doi.org/10.1590/S0104-59702015000400004>. Acesso em: 5 fev. 2017.

SILVA, H. C. Reforma psiquiátrica nas medidas de segurança: a experiência goiana do PAILI. Revista Brasileira de Crescimento e Desenvolvimento Humano, v. 20, n. 1, p. 112-115, 2010. Disponível em: <http://pepsic.bvsalud.org/pdf/rbcdh/v20n1/15.pdf>. Acesso em: 3 fev. 2017.

TABORDA, J. G. V.; BINS, H. D. C. Exame Pericial Psiquiátrico. In: ABDALLA-FILHO, E.; CHAlUB, M.; TELLES, L. E. B. Psiquiatria Forense de Taborda. 3 .ed. Porto Alegre: Artmed, 2016. Cap. 4.

TABORDA, J. G. V.; CHALUB, M.; COSTA, G. M. Perícia de Imputabilidade Penal. In: ABDAllA-FIlHO, E.; CHALUB, M.; TELlES, L. E. B. Psiquiatria Forense de Taborda. 3. ed. Porto Alegre: Artmed, 2016. Cap. 8.

\section{Notas}

${ }^{1}$ A. S. Oliveira foi responsável pela obtenção, análise, interpretação dos dados e redação do manuscrito. F. M. V. Dias realizou a concepção do projeto de pesquisa, redação do manuscrito e revisão crítica. 


\section{Abstract}

\section{Going Backwards: The fate of the individual with mental disorder that commit crimes in Brazil}

Psychiatric reform in Brazil made it possible, among other benefits, to replace the psychiatric medical model with the psychosocial care model. Psychiatric hospitalization is now contraindicated, except in cases in which extra-hospital resources are inadequate or when judicially indicated. In such cases, assistance to mentally ill people who are perpetrators of crime is carried out in the Custody and Psychiatric Treatment Facilities (ECTP), where these individuals are hospitalized for compliance with the security measure imposed. Between 2015 and 2016, the National Mechanism for Combating and Preventing Torture (Mecanismo Nacional de Combate e Prevenção à Tortura - MNCPT, in Portuguese) carried out the inspection of detention units, releasing reports describing its current situation. To date, five custody establishments have been visited in the states of Pará, Paraíba, Rio Grande do Sul, Rondônia and São Paulo. This article discusses the right to health in the context of ECTPs. Circulating between the domains of law and medicine, this population has their human rights violated and, although geographically distant, it is unanimous that advances in mental health care have not addressed ECTPs, which still preserve asylum characteristics.

> Keywords: Custody and Psychiatric Hospital; crime; mental illness patient; security measures; Psychosocial Attention Network. 